\title{
Perancangan dan Analisis Kinerja Sistem Kontrol dan Penjadwalan Lampu Berbasis IoT
}

\author{
ADNAN RAFI AL TAHTAWI'1, TRISIANI DEWI HENDRAWATI ${ }^{2}$, \\ AIM ABDURRAHIM ${ }^{3}$, ERICK ANDIKA 4
}

\author{
1]urusan Teknik Elektro, Politeknik Negeri Bandung \\ 2,3,4Program Studi Teknik Komputer, Politeknik Sukabumi \\ Email: adnan.raf@polban.ac.id
}

Received 11 Mei 2019 | Revised 7 Juli 2019 | Accepted 21 Agustus 2019

\begin{abstract}
ABSTRAK
Pengontrolan lampu melalui jaringan internet adalah salah satu contoh aplikasi berbasis teknologi Internet of Things (IoT). Tujuan penelitian ini adalah untuk merancang sistem kontrol dan penjadwalan lampu berbasis IoT, serta melakukan analisis terhadap kinerja sistem tersebut. Sistem ini dibangun menggunakan mikrokontroler NodeMCU yang telah terintegrasi dengan modul WiFi. Pengendali relai dirancang dengan algoritma sederhana menggunakan objek tombol di aplikasi Android sebagai perangkat antarmuka. Selain memberikan perintah secara langsung, aplikasi Android juga dirancang agar dapat menjadwalkan ON/OFF lampu melalui akses akun pengguna. Hasil pengujian menunjukkan bahwa sistem dapat terhubung dengan jaringan internet melalui modul WiFi. Lampu berhasil dikontrol dan dijadwalkan sesuai dengan beberapa skenario pengujian. Hasil uji waktu respon pengiriman data menunjukkan bahwa waktu tunda rata-rata pengiriman perintah dari aplikasi Android ke sistem adalah kurang dari 5 detik.
\end{abstract}

Kata kunci: NodeMCU, IoT, sistem kontrol, penjadwalan, Android

\begin{abstract}
Lighting control over the internet network is one example of Internet of Things (IOT) applications. The aim of this research is to design a light control and scheduling system based on IoT, and also to analyze its performances. This system is built using low-cost NodeMCU microcontroller that has integrated with the WiFi module. Relay controller is designed with simple algorithm using push button object in an Android application as an interface device. Besides giving command directly, the Android application is also designed to schedule ON/OFF the lights through user account access. The testing results indicate that the system able to connect with internet network via WiFi module. The lights are sucessfully controlled and scheduled according to several testing scenarios. Time respon testing result shows that the average delay data transmission from Android application to system hardware is less than 5 seconds.
\end{abstract}

Keywords: NodeMCU, IoT, control system, scheduling, Android 
Tahtawi, dkk

\section{PENDAhuluan}

Penggunaan energi listrik harus dilakukan secara efisien oleh manusia dalam upaya mengurangi risiko pemanasan global. Energi listrik di rumah-rumah seringkali tidak dikelola dengan baik oleh penghuninya. Salah satu kebiasaan buruk penggunaan energi listrik yang paling sering dilakukan adalah membiarkan lampu menyala (Deesing, 2016). Terkadang penghuni rumah tidak bijak dalam menggunakan lampu dan tidak sesuai dengan kebutuhan. Selain itu, ketika penghuni meninggalkan rumah dalam waktu lama, mereka tidak dapat mengontrol kondisi lampu rumah. Dengan demikian, diperlukan suatu sistem yang dapat mengontrol lampu dari jarak jauh. Salah satu teknologi yang memungkinkan digunakan untuk mengatasi permasalahan tersebut yaitu internet atau disebut Internet of Things (IoT).

IoT adalah konsep yang dapat menggabungkan teknologi internet dan sistem fisik (Miorandi, dkk, 2012). Tantangan desain praktis dari IoT menjadi tugas utama yang harus dipertimbangkan dalam merancang aplikasi IoT (Stojkoska \& Trivodaliev, 2017). Sistem IoT dapat dibangun pada skala prototipe hingga implementasi yang sebenarnya. Kinerja pada skala prototipe dapat digunakan sebagai langkah awal sebelum fase implementasi dilakukan (Gunawan, dkk, 2018). Dalam merancang sistem IoT, khususnya untuk rumah pintar, beberapa karakteristik utama seperti kompleksitas sistem yang rendah, keandalan dan portabilitas yang tinggi, ramah pengguna, dan konsumsi daya yang rendah harus dapat diatasi (Adiono, dkk, 2016). Setiap subsistem pada rumah pintar memiliki tugas yang harus dilakukan sesuai dengan kebutuhan pengguna.

Beberapa solusi untuk mengatasi masalah kontrol lampu di rumah pintar telah disajikan dengan menggunakan konsep IoT. Sistem kontrol lampu untuk rumah pintar telah dirancang menggunakan Arduino menggunakan antarmuka Android (Coca \& Hernandez, 2018). Referensi terakhir memungkinkan pengguna untuk menjalankan kontrol ON/OFF, kontrol intensitas, kontrol gerak, kontrol berbasis pencahayaan atau mode otomatis, dan kontrol terprogram menggunakan NodeMCU (Chandramohan, dkk, 2017).

Penelitian ini bertujuan untuk merancang sistem kontrol dan penjadwalan lampu berbasis IoT dan melakukan analisis terhadap kinerja sistem tersebut. Sistem ini dirancang menggunakan mikrokontroler NodeMCU sebagai perangkat pengolah sinyal dan Android sebagai antarmuka pengguna. Perangkat mikrokontroler ini dapat dengan mudah diperoleh di pasaran dan memiliki karakteristik berbiaya rendah. Perangkat ini juga banyak digunakan oleh para peneliti dan akademisi dalam merancang sistem IoT (Adriansyah \& Dani, 2014), (Mahindar, dkk, 2018), (Qiang, dkk, 2018). Di sisi perangkat lunak, sistem ini terintegrasi dengan layanan web dan komputasi awan untuk sistem kontrol dan pemantauan (Moward, dkk, 2014), (Bimenyimana, dkk, 2018). Berbeda dengan beberapa sistem serupa yang telah dirancang sebelumnya, pada penelitian ini aplikasi Android dikembangkan dengan fitur kontrol dan penjadwalan yang hanya dapat diakses melalui akun pengguna. Dengan konsep ini, maka keamanan akses pengguna akan lebih terjaga. Sistem ini diuji pada beberapa subsistem dasar seperti konektifitas jaringan internet, pengontrolan dan penjadwalan, serta respon waktu perintah dari antarmuka pengguna ke perangkat keras. Dengan memanfaatkan teknologi IoT, maka pengontrolan dan penjadwalan perangkat elektronik seperti lampu di rumah dapat dilakukan dimanapun sehingga dapat mengefisiensi penggunaan konsumsi energi listrik. 


\section{METODE PENELITIAN}

\subsection{Tahapan Penelitian}

Metode yang digunakan pada penelitian ini adalah eksperimen dengan tahapan penelitian yang dilakukan seperti ditunjukkan Gambar 1.

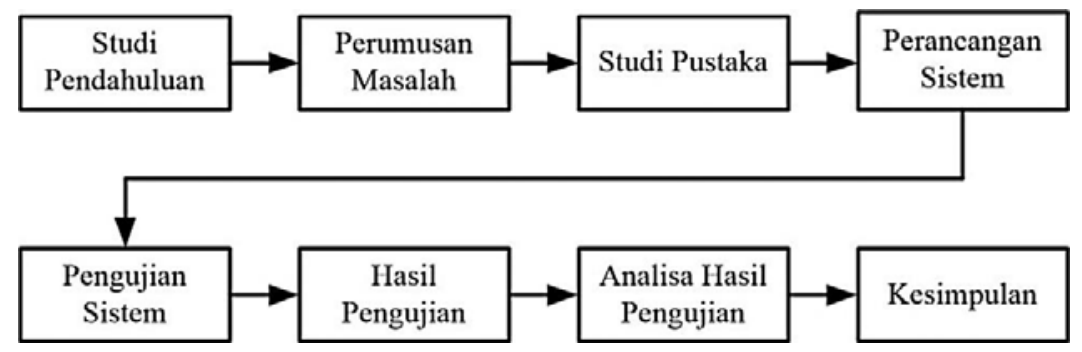

Gambar 1. Tahapan Penelitian

Adapun penjelasan dari tahapan penelitian yang dilakukan adalah sebagai berikut:

1. Studi pendahuluan, tahap ini merupakan tahapan awal penelitian yang bertujuan untuk mengidentifikasi permasalahan yang ada.

2. Perumusan masalah, pada bagian ini dirumuskan permasalahan yang diperoleh dari studi pendahuluan.

3. Studi pustaka, tahap ini dilakukan untuk memperoleh data-data penelitian sebelumnya dan teori pendukung untuk penelitian ini.

4. Perancangan sistem, pada tahap ini dilakukan perancangan perangkat keras, perangkat lunak, dan algoritma pengontrolan.

5. Pengujian sistem, pada bagian ini dirancang beberapa skenario pengujian untuk mengetahui kinerja dari sistem yang dirancang.

6. Hasil pengujian, pada tahap ini data-data hasil pengujian dikumpulkan untuk dilakukan analisis.

7. Analisis hasil pengujian, setelah diperoleh hasil pengujian selanjutnya dilakukan analisis terhadap hasil tersebut baik dalam bentuk tabel maupun grafik.

8. Kesimpulan, langkah terakhir adalah menarik kesimpulan terhadap hasil pengujian yang didapatkan.

\subsection{Perancangan Sistem}

Pada dasarnya, sistem ini dirancang untuk mengontrol dan menjadwalkan ON/OFF lampu. Sistem ini menggabungkan rangkaian listrik pada lampu menjadi satu sistem yang terpadu. Dengan sistem ini, pengguna tidak mengontrol lampu melalui saklar mekanis. Pengguna dapat mengontrol, memantau, dan dapat mengatur waktu untuk menyalakan dan memadamkan lampu sesuai kebutuhan mereka menggunakan aplikasi Android. Sistem ini dikontrol oleh aplikasi yang terhubung internet pada perangkat Android untuk setiap lampu. Untuk kelengkapan, sistem yang dirancang dalam penelitian ini memiliki beberapa spesifikasi yang diharapkan sebagai berikut:

1. Menyalakan dan memadamkan lampu dengan tombol ON/OFF pada aplikasi Android.

2. Mengontrol jumlah lampu dengan memilih beberapa atau semua lampu yang akan dihidupkan atau dimatikan sesuai kebutuhan.

3. Mengatur waktu untuk menyalakan dan memadamkan lampu sesuai kebutuhan.

4. Menampilkan status lampu ketika dinyalakan dan dimatikan saat memantau pengguna. 
5. Menyimpan data aktivitas di web server untuk kebutuhan analisis data.

\subsection{Perangkat Keras}

Sistem perangkat keras dibuat dalam bentuk prototipe untuk kesederhanaan. Perangkat keras yang digunakan terdiri dari input, proses, output, dan indikator/tampilan. Pada bagian input, terdapat smartphone Android yang berfungsi sebagai perangkat pengontrol. Pada bagian proses, terdapat modul mikrokontroler NodeMCU yang terintegrasi dengan modul WiFi ESP8266. Fungsi perangkat ini adalah untuk menerima sinyal dari perangkat smartphone Android, memproses sinyal, dan memberikan sinyal ke perangkat output. Pada output dan indikator/tampilan, terdapat modul relai SPDT 6 saluran, 6 unit lampu, LED, dan layar LCD yang berfungsi sebagai output sistem dan indikator tampilan. Spesifikasi perangkat keras secara keseluruhan dapat dilihat pada Tabel 1. Desain perangkat keras dalam penelitian ini juga dapat dilihat pada Gambar 1.

Tabel 1. Spesifikasi Perangkat Keras

\begin{tabular}{|l|l|c|}
\hline \multicolumn{1}{|c|}{ Perangkat keras } & \multicolumn{1}{|c|}{ Spesifikasi } & Keterangan \\
\hline Android Smartphone & Operating System & Android version 4.4 (KitKat) \\
\hline & Processor & $800 \mathrm{Mhz}$ \\
\hline & RAM & $512 \mathrm{MB}$ \\
\hline & Internal Memory & VB \\
\hline & Version & ESP8266-ESP12E \\
\hline & Microcontroller & Tensilica L106 32-bit \\
\hline & Prosesor & $50 \mathrm{~mm} \times 25 \mathrm{~mm}$ \\
\hline & Size & 13 pin \\
\hline & GPIO & 10 pin \\
\hline & PWM Pin & $4 \mathrm{Pin}(10 \mathrm{bit})$ \\
\hline & ADC Pin & $4 \mathrm{MB}$ \\
\hline & Flash Memory & $40 / 26 / 24 \mathrm{MHz}$ \\
\hline & Clock Speed & IEEE 802.11 b/g/n \\
\hline & WiFi & $2.4 \mathrm{GHz}-22.5 \mathrm{GHz}$ \\
\hline Relay & Frequency & Single Pole Double Throw (SPDT) \\
\hline & Type & $10 \mathrm{~A} / 250 \mathrm{VAC}, 10 \mathrm{~A} / 30 \mathrm{VDC}$ \\
\hline & Output Maximum & $5 \mathrm{~V}$ \\
\hline Lights & Vcc & $220 \mathrm{VAC}$ \\
\hline & Voltage & 7 Watt (4 units), 5 Watt (2 units) \\
\hline
\end{tabular}

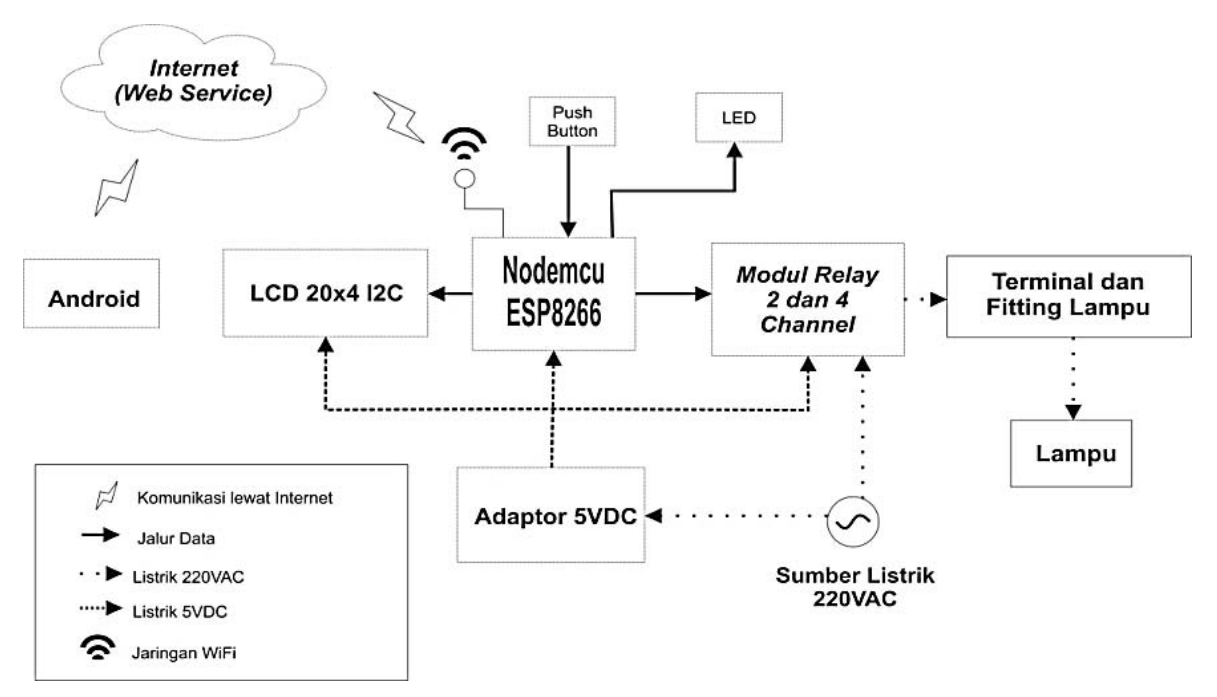

Gambar 1. Rancangan Perangkat Keras 
Dalam penelitian ini, sistem menggunakan 6 saluran relai SPDT yang terhubung satu sama lain. Pada bagian ini, kami menambahkan beberapa komponen pendukung termasuk 2 unit transistor PNP S9012, 1 unit transistor NPN S9013, 1 unit resistor 270 , 2 unit resistor $1 \mathrm{k} \Omega$, dan 1 unit resistor $10 \mathrm{k} \Omega$ seperti yang digambarkan pada Gambar 2 dengan tanda garis merah putus-putus. Komponen-komponen ini digunakan sebagai pengkondisi nilai-nilai logika yang dihasilkan oleh relai, seperti keberadaan kondisi aktif rendah dan adanya histeresis. Aktif rendah adalah suatu kondisi di mana relai merespon logika rendah, sementara histeresis adalah perilaku dimana sistem gagal untuk kembali ke keadaan semula atau sebelumnya setelah penyebab perubahan ini dihilangkan. Dengan menggunakan sirkuit tambahan ini, sistem relai diharapkan bekerja dengan baik dan stabil. Adapun detail koneksi setiap pin pada sistem ini disajikan pada Tabel 2.

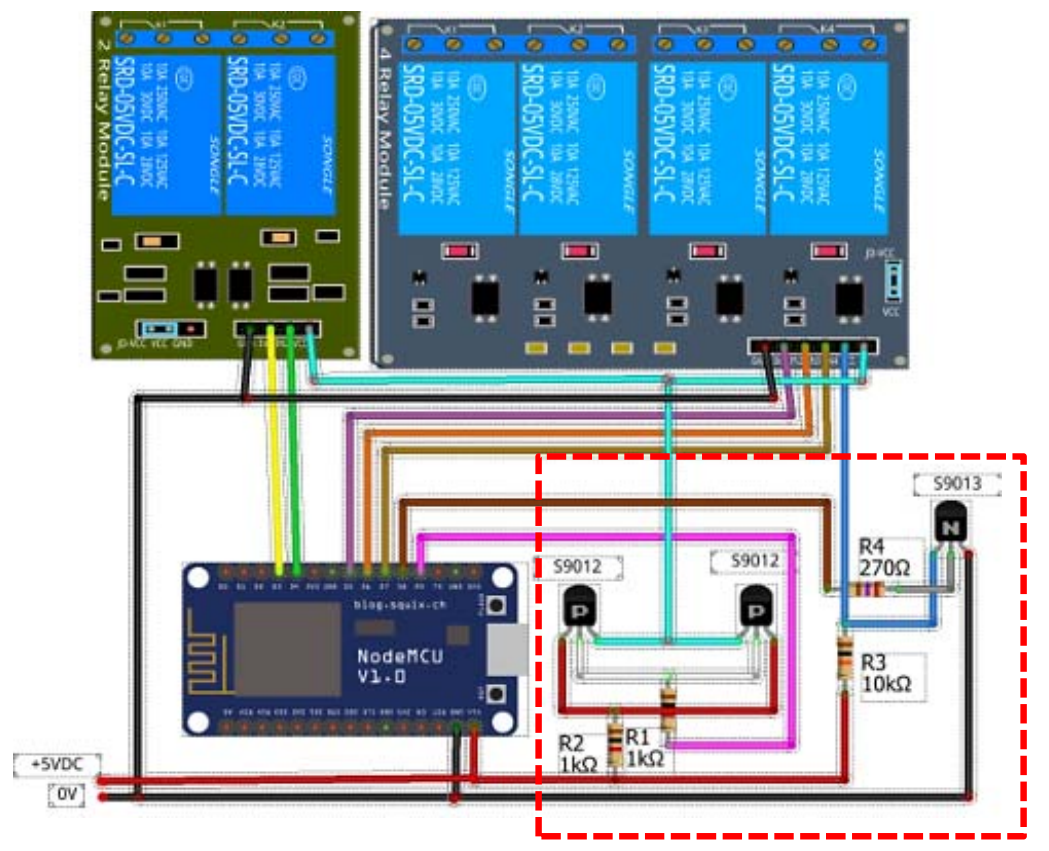

Gambar 2. Skematik Rangkaian dengan Pengkondisi Sinyal Relai

Tabel 2. Konfigurasi Pin Modul Relai dan NodeMCU

\begin{tabular}{|c|c|c|c|c|}
\hline \multirow{2}{*}{$\begin{array}{c}\text { Pin } \\
\text { NodeMCU }\end{array}$} & \multicolumn{2}{|c|}{ Modul Relai } & \multirow{2}{*}{ Warna Kabel } & \multirow{2}{*}{ Keterangan } \\
\hline & 4 Kanal & 2 Kanal & & \\
\hline D3 & - & IN1 & Kuning & - \\
\hline D4 & - & IN2 & Hijau & - \\
\hline D5 & IN1 & - & Ungu & - \\
\hline D6 & IN2 & - & Jingga & - \\
\hline D7 & IN3 & - & Kuning tua & - \\
\hline D8 & IN4 & - & $\begin{array}{l}\text { Coklat, Abu- } \\
\text { abu, Biru, } \\
\text { Hitam, Merah }\end{array}$ & \multirow{4}{*}{$\begin{array}{l}\text { Ditambahkan komponen dua } \\
\text { buah resistor } 1 \mathrm{k} \Omega \text {, satu } \\
\text { buah resistor } 10 \mathrm{k} \Omega \text {, satu } \\
\text { buah resistor } 270 \Omega \text { dua } \\
\text { buah transistor } \mathrm{S} 9012 \text { dan } \\
\text { satu buah transistor } S 9013 \text {. }\end{array}$} \\
\hline D9 & VCC & VCC & $\begin{array}{l}\text { Merah Muda, } \\
\text { Putih, Biru } \\
\text { Kehijauan, } \\
\text { Merah }\end{array}$ & \\
\hline GND & GND & GND & Hitam & \\
\hline Vin & - & - & Merah & \\
\hline
\end{tabular}




\subsection{Perangkat Lunak}

Di bagian perangkat lunak, aplikasi Android dirancang sebagai antarmuka pengguna. Aplikasi ini dirancang dengan beberapa fitur seperti pendaftaran, login, membuat saluran, menghapus saluran, mengendalikan satu lampu, mengendalikan beberapa lampu, mengendalikan semua lampu, dan menjadwalkan lampu. Pengguna harus mendaftarkan diri di aplikasi Android sehingga data dapat disimpan ke dalam database melalui layanan web. Jika akun sudah dibuat, pengguna dapat masuk ke aplikasi Android dan tampilan "My Channel" akan muncul. Pengguna harus menambahkan saluran baru untuk disimpan dalam database. Setelah itu, layanan web akan mengirim data JSON yang telah diambil dari database untuk diuraikan dalam aplikasi Android.

Data JSON adalah data yang harus dimasukkan ke dalam pemrograman NodeMCU sehingga dapat terhubung dengan Android melalui jaringan internet dan layanan web. Setelah NodeMCU terhubung dengan Android, maka akan merespon aplikasi Android untuk dapat mengendalikan sistem. Selain itu, NodeMCU akan mengambil data waktu dari server NTP (Network Time Protocol) untuk mengatur waktu menyalakan dan memadamkan lampu. Pemrograman dilakukan menggunakan bahasa pemrograman $\mathrm{C} / \mathrm{C}++$ pada Arduino IDE dimana terlebih dahulu dipasang library untuk papan mikrokontroler NodeMCU. Pada pemrograman melalui Arduino IDE, disusun algoritma yang terdiri dari proses inisialisasi dan konfigurasi pin I/O, algoritma pengontrolan dan penjadwalan, serta proses komunikasi antara perangkat keras dengan antarmuka Android.

Adapun desain konfigurasi hubungan komunikasi terperinci antara perangkat keras dan jaringan internet dapat dilihat pada Gambar 3, sedangkan diagram alir algoritma pengontrolan dan penjadwalan dari sistem yang dirancang dapat dilihat pada Gambar 4. Seperti dapat dilihat bahwa desain sistem komunikasi antara pengguna dan sistem dibuat dengan memanfaatkan jaringan internet. Konsep ini dapat dibuat dalam domain private maupun public. Dengan menggunakan aplikasi Android, pengguna dapat mengontrol kondisi lampu sesuai kebutuhan. Pada bagian diagram alir, pengguna dapat mengoperasikan aplikasi jika telah melakukan proses login. Kemudian pengguna membuat channel sesuai kebutuhan pengontrolan dan penjadwalan. Algoritma pengoperasian ini dibuat sederhana agar dapat dengan mudah dioperasikan pengguna.

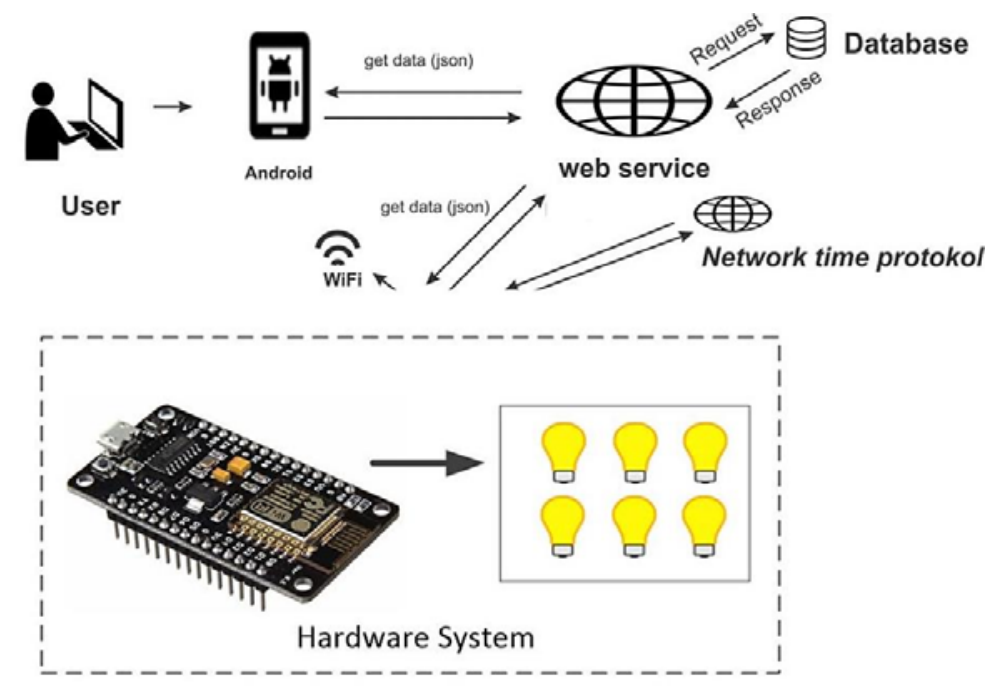

Gambar 3. Perancangan Sistem Komunikasi 


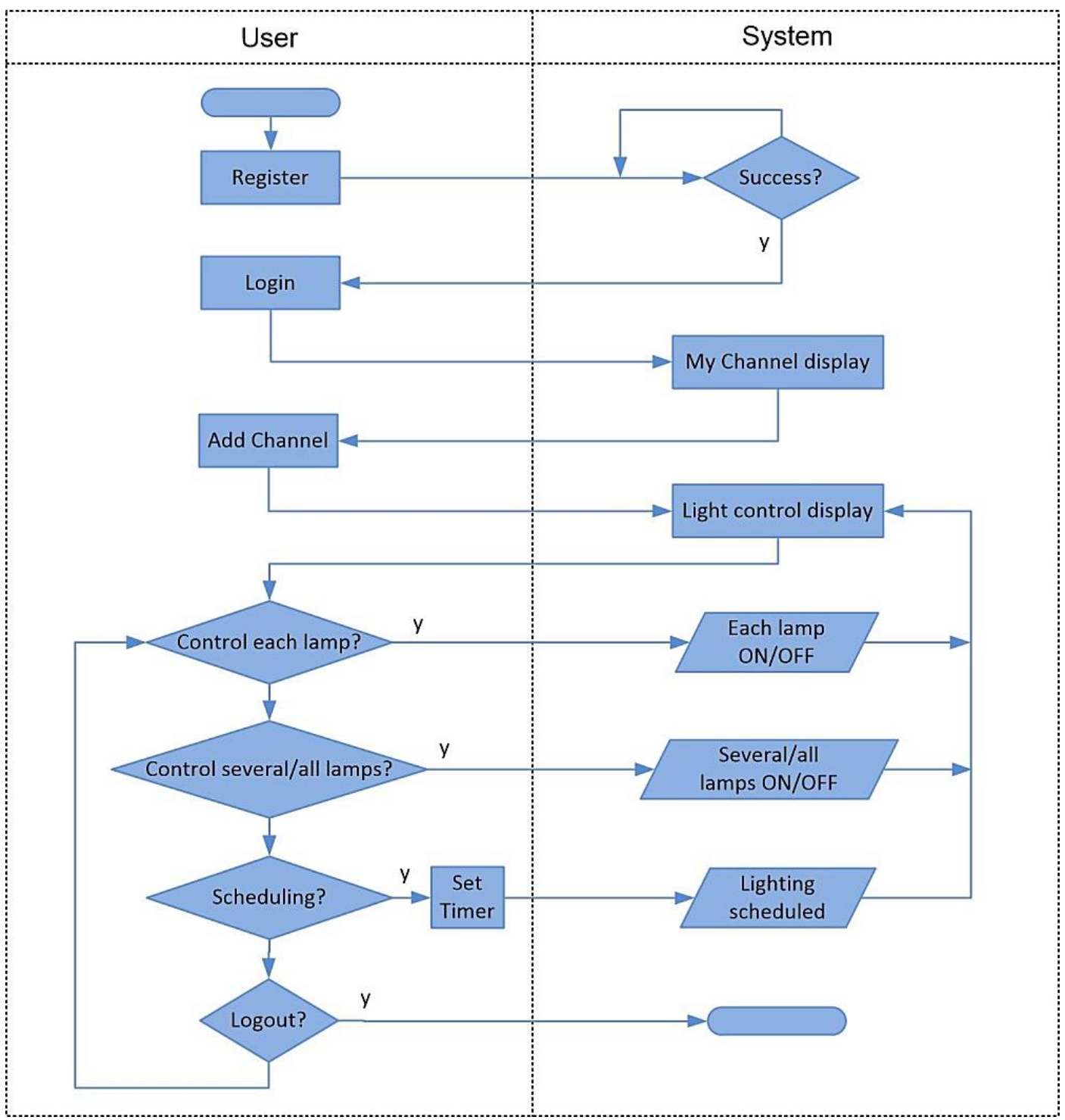

Gambar 4. Diagram Alir Sistem

\section{HASIL DAN PEMBAHASAN}

Pada tahap ini, implementasi perangkat keras dan lunak dilakukan sesuai dengan desain yang dijelaskan sebelumnya. Sistem perangkat keras diimplementasikan dalam bentuk purwarupa menggunakan 6 unit lampu dengan daya 7 Watt sebanyak 4 buah dan daya 5 Watt sebanyak 2 buah. Perangkat lunak dalam hal ini aplikasi Android juga diimplementasikan pada sistem operasi Android 4.4 Kitkat pada smartphone sesuai dengan spesifikasi pada Tabel 1. Hasil implementasi perangkat keras dan perangkat lunak aplikasi Android dapat dilihat pada Gambar 5. Setelah dilakukan implementasi, kemudian sistem diuji untuk menentukan kinerja keseluruhan. Pengujian yang dilakukan meliputi pengujian koneksi internet, pengujian aplikasi Android untuk pengontrolan/penjadwalan, dan pengujian waktu tunda. Ketiga pengujian ini dianggap dapat mewakili kinerja sistem secara keseluruhan. 
Tahtawi, dkk
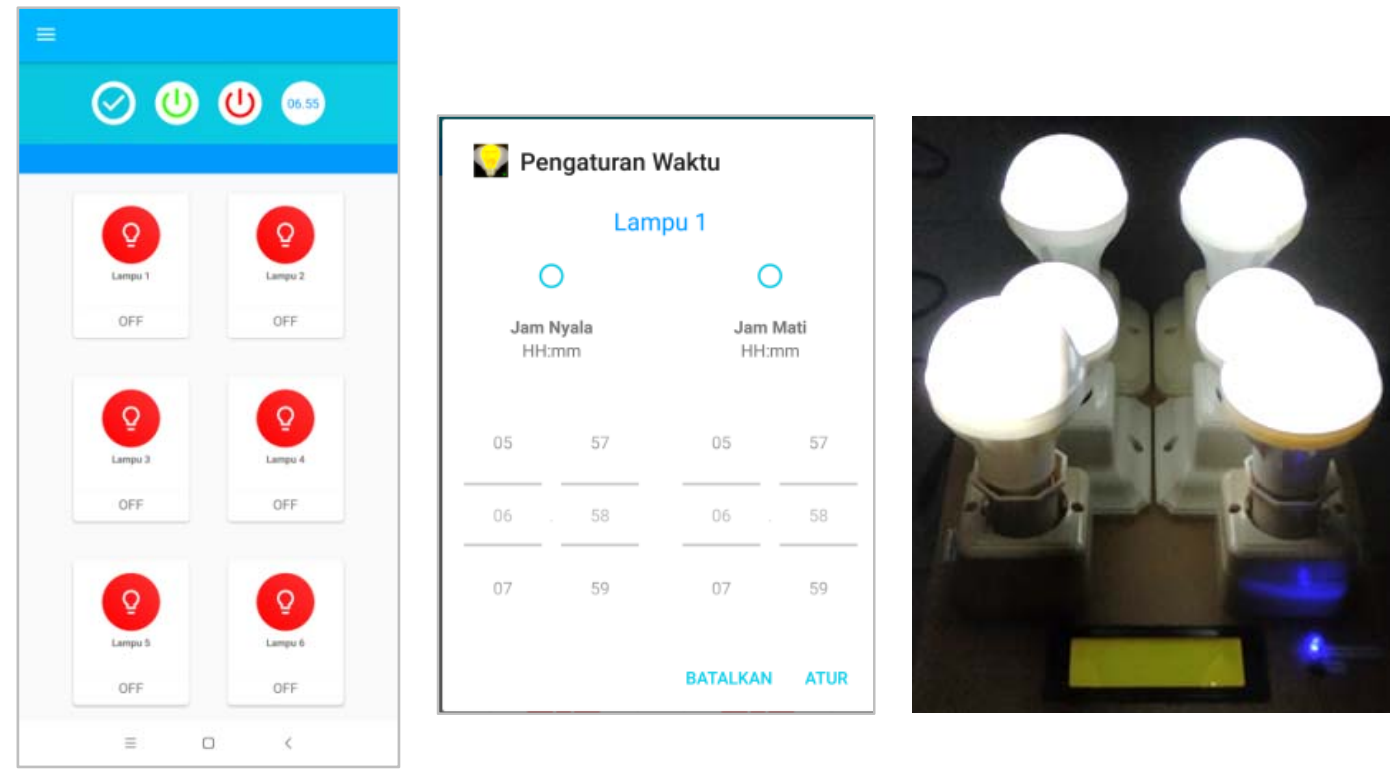

Gambar 5. Implementasi Sistem

\subsection{Hasil Pengujian}

Setelah dilakukan tahap implementasi, selanjutnya sistem diuji untuk mengetahui performansinya. Pengujian pertama bertujuan untuk mengetahui konektivitas dari sistem terhadap jaringan internet. Pengujian dilakukan dengan menghidupkan perangkat dan menunggu hingga terhubung ke jaringan WiFi yang dihasilkan melalui sinyal GSM pada smartphone. Gambar 6 dan Gambar 7 menunjukkan hasil bahwa sistem dapat dihubungkan ke jaringan WiFi "sorangan" dengan alamat IP 192.168.43.249 dan dapat terhubung ke jaringan internet. Setelah terhubung ke internet, dengan demikian sistem dapat terhubung ke layanan web server dan dapat menyimpan data.

Terhubung ke WiFi

'sorangan'

IP Address :

192.168 .43 .249

Gambar 6. Pengujian Konektifitas Internet pada LCD

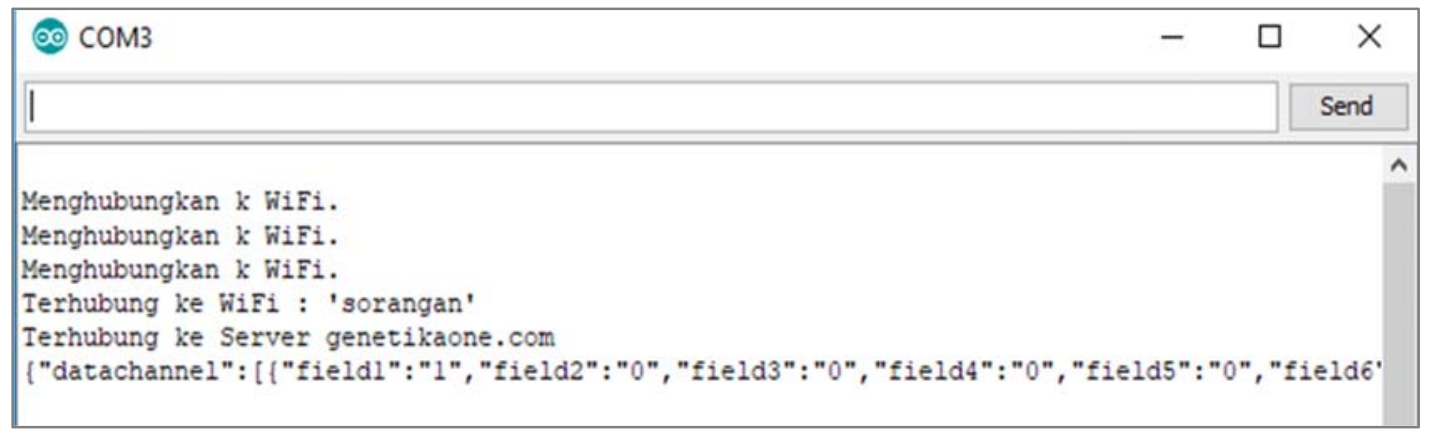

Gambar 7. Pengujian Konektifitas Internet pada Serial Monitor 
Selanjutnya, pengujian kedua dilakukan untuk mengetahui kinerja aplikasi Android yang telah dirancang. Pengujian dilakukan dengan memberikan perintah ON/OFF dan menjadwalkan lampu. Hasil pengujian dapat dilihat pada Tabel 3. Berdasarkan hasil pengujian melalui beberapa skenario, aplikasi Android yang dirancang mampu mengontrol dan menjadwalkan lampu meskipun masih ada keterlambatan dalam pengiriman data. Keterlambatan ini kemudian diuji dan dianalisis pada pengujian ketiga.

Tabel 3. Pengujian Aplikasi Android

\begin{tabular}{|c|l|c|}
\hline Skenario Ke- & \multicolumn{1}{|c|}{ Perintah } & Hasil Pengujian \\
\hline 1 & Hidupkan satu lampu & Berhasil \\
\hline 2 & Matikan satu lampu & Berhasil \\
\hline 3 & Hidupkan beberapa lampu & Berhasil \\
\hline 4 & Matikan beberapa lampu & Berhasil \\
\hline 5 & Hidupkan semua lampu & Berhasil \\
\hline 6 & Matikan semua lampu & Berhasil \\
\hline 7 & Jadwalkan lampu hidup & Berhasil \\
\hline 8 & Jadwalkan lampu mati & Berhasil \\
\hline 9 & Jadwalkan lampu hidup dan mati & Berhasil \\
\hline
\end{tabular}

Pengujian ketiga dilakukan untuk menentukan waktu tunda ketika kontrol lampu dilakukan. Pengujian dilakukan dengan memberikan perintah ke setiap lampu melalui beberapa percobaan. Hasil pengujian keterlambatan dapat dilihat pada Gambar 8. Berdasarkan hasil ini, dapat dilihat bahwa ada keterlambatan pengiriman data saat kontrol lampu dilakukan. Penundaan tercepat 3,16 detik terjadi pada pengujian ketiga Lampu 5, sedangkan penundaan terlama adalah 6,29 detik pada pengujian ketiga Lampu 6 . Hasil rata-rata waktu tunda adalah 4,73 detik. Perbedaan waktu tunda ini disebabkan oleh kondisi jaringan internet pada saat pengujian. Namun, hasil ini masih dapat diterima dan seperti yang diharapkan.

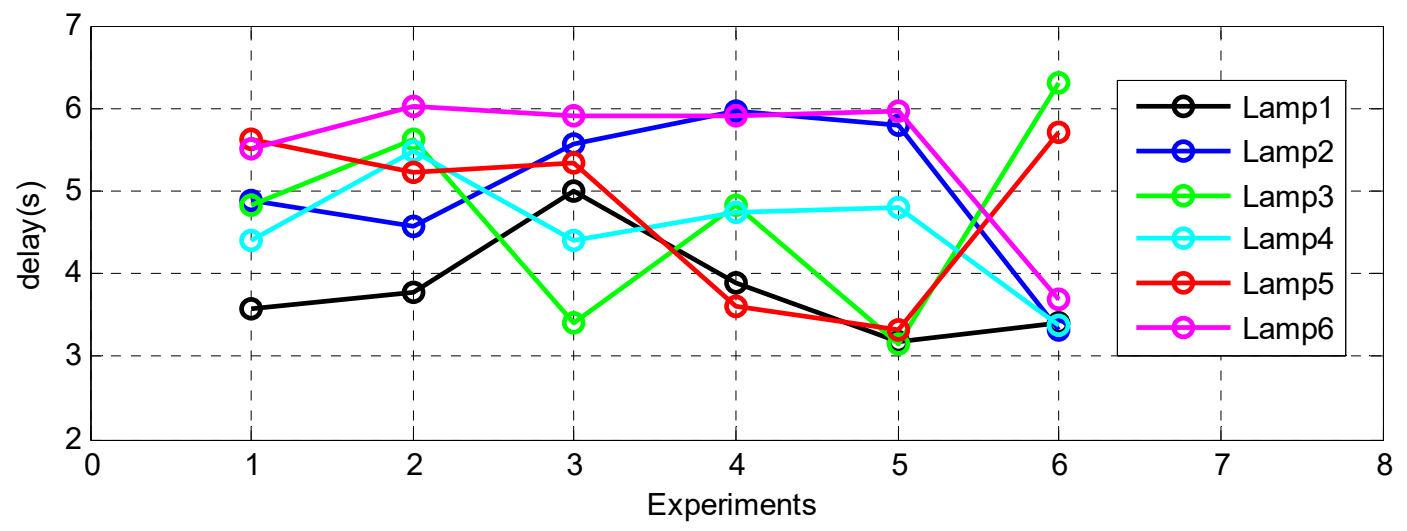

Gambar 7. Pengujian Waktu Tunda

\subsection{Pembahasan}

Kelebihan dari sistem ini adalah dapat memberikan kontrol lampu yang mudah atau perangkat elektronik lainnya dari jarak jauh melalui internet. Perangkat keras sistem ini tidak memerlukan kabel jaringan untuk menghubungkan sistem ke internet karena dilengkapi dengan modul WiFi. Mikrokontroler NodeMCU memiliki karakteristik berbiaya rendah dan lebih sederhana dalam desain dan implementasi jika dibandingkan dengan modul mikrokontroler lain seperti Arduino. Papan ini memberikan beberapa keuntungan, terutama dalam integrasi dengan modul WiFi ESP8266 yang tidak dimiliki oleh modul mikrokontroler lain. NodeMCU memiliki 
Tahtawi, dkk

modul WiFi dengan biaya terendah yaitu kurang dari 2 USD dibandingkan dengan Arduino yang memiliki harga 22 USD. Dengan demikian, sistem ini dapat dirancang dengan biaya yang relatif rendah. Selain itu, aplikasi Android yang dirancang dilengkapi dengan sistem keamanan yang memanfaatkan informasi akun pengguna dan kata sandi. Fasilitas ini memungkinkan pengguna untuk mengontrol dan menjadwalkan lampu menggunakan akun mereka. Dengan menggunakan akun pengguna, keamanan dari sistem IoT ini juga dapat dicapai. Dari sisi kinerja, sistem ini juga dapat memberikan performansi yang handal dimana ditandai dengan hasil pengujian konektifitas, skenario pengontrolan dan penjadwalan, serta waktu respon yang baik. Namun demikian, sistem ini tidak dilengkapi dengan sensor arus seperti pada (Hendrawati, dkk, 2018) sehingga tidak dapat mengetahui penggunaan daya dari setiap lampu. Penelitian lebih lanjut dapat dilakukan untuk pengembangan sistem ini seperti integrasi dengan sistem pemantauan daya, pembuatan perangkat keras yang handal, dan implementasi aktual pada sistem rumah pintar.

\section{KESIMPULAN}

Sistem kontrol dan penjadwalan lampu menggunakan NodeMCU dan konsep IoT telah berhasil dirancang dan diuji. Perangkat keras sistem ini dapat dibangun menggunakan modul NodeMCU berbiaya rendah yang terintegrasi dengan fasilitas WiFi. Sistem ini mampu mengontrol dan menjadwalkan ON/OFF lampu sesuai dengan kebutuhan pengguna. Sistem kontrol dan penjadwalan dilakukan menggunakan aplikasi Android dengan akun pengguna dan kata sandi untuk sistem keamanan. Berdasarkan hasil pengujian dengan beberapa skenario, kontrol lampu dan sistem penjadwalan dapat dilakukan menggunakan aplikasi Android melalui komunikasi internet. Rata-rata waktu tunda yang diperoleh dari hasil tes adalah 4,73 detik. Kondisi ini bergantung pada koneksi internet yang digunakan untuk sistem ini pada waktu pengujian. Penelitian selanjutnya diperlukan untuk pengembangan sistem ini seperti integrasi dengan sistem pemantauan daya setiap perangkat elektronik di rumah pintar.

\section{UCAPAN TERIMA KASIH}

Ucapan terima kasih disampaikan kepada Laboratorium Elektro, Program Studi Teknik Komputer, Politeknik Sukabumi yang telah membantu dalam hal penyediaan fasilitas.

\section{DAFTAR RUJUKAN}

Adiono, T., Putra, R. V. W., Fathany, M. Y., Lawu, B. L., Afifah, K., Santriaji, M. H., \& Fuada, S. (2016). Rapid Prototyping Methodology of Lightweight Electronic Drivers for Smart Home Appliances. International Journal of Electrical \& Computer Engineering, 6(5), 20888708.

Adriansyah, A., \& Dani, A. W. (2014). Design of small smart home system based on Arduino. In 2014 Electrical Power, Electronics, Communicatons, Control and Informatics Seminar (EECCIS), (pp. 121-125).

Bimenyimana, S., Ishimwe, A., Asemota, G. N. O., Kemunto, C. M., \& Li, L. (2018, June). Web-

Based Design and Implementation of Smart Home Appliances Control System. In IOP Conference Series: Earth and Environmental Science, (pp. 012-017). 
Chandramohan, J., Nagarajan, R., Satheeshkumar, K., Ajithkumar, N., Gopinath, P. A., \& Ranjithkumar, S. (2017). Intelligent smart home automation and security system using Arduino and Wi-fi. International Journal of Engineering And Computer Science (IJECS), 6(3), 20694-20698.

Coca, L., \& Hernández, C. (2018). Technological Proposal for Controlling a Residential Lighting System. International Journal of Applied Engineering Research, 13, 9579-9587.

Deesing, J. (2016). The 10 Biggest Energy Wasting Habits at Home. Retrieved from https://www.ase.org/blog/10-biggest-energy-wasting-habits-home

Gunawan, T. S., Yaldi, I. R. H., Kartiwi, M., \& Mansor, H. (2018). Performance Evaluation of Smart Home System using Internet of Things. International Journal of Electrical and Computer Engineering, \&(1), 400.

Hendrawati, T. D., Wicaksono, Y. D., \& Andika, E. (2018). Internet of Things: Sistem KontrolMonitoring Daya Perangkat Elektronika. JTERA (Jurnal Teknologi Rekayasa), 3(2), 177184.

Mahindar, R., Prakash, M., Ghosh, S., Mukherjee, S., \& Ghosh, R. (2018). IoT-based Home Appliances Control System Using NodeMCU and Blynk Server. International Advanced Research Journal in Science, Engineering and Technology, 5, 16-22.

Miorandi, D., Sicari, S., De Pellegrini, F., \& Chlamtac, I. (2012). Internet of things: Vision, applications and research challenges. Ad hoc networks, 10(7), 1497-1516.

Mowad, M. A. E. L., Fathy, A., \& Hafez, A. (2014). Smart home automated control system using android application and microcontroller. International Journal of Scientific \& Engineering Research, 5(5), 935-939.

Qiang, T., Guangling, G., Lina, C., \& Han, W. (2018). Nodemcu-based Low-cost Smart Home Node Design. IOP Conference Series: Materials Science and Engineering, (pp. 012013).

Stojkoska, B. L. R., \& Trivodaliev, K. V. (2017). A review of Internet of Things for smart home: Challenges and solutions. Journal of Cleaner Production, 140, 1454-1464. 